\title{
Biochemical Changes in Alloxan - Induced Diabetes Rat Liver and Kidney Dosed Artesunate
}

\author{
L.W.B Olaniyan ${ }^{1} \quad$ E.O Olagoke ${ }^{1 *} \quad$ M. A. Abdulrasak ${ }^{1} \quad$ A. Z Lawal ${ }^{2}$ \\ E. F Adeogun ${ }^{3} \quad$ K.O Adefemi ${ }^{4}$ \\ 1.Department of Biochemistry, Faculty of Basic Medical Sciences, College of Health Sciences, Ladoke Akintola \\ University of Technology, Ogbomoso, Oyo State, Nigeria \\ 2.Department of Medical Biochemistry, Faculty of Basic Medical Sciences, College of Health Sciences, \\ University of Ilorin, Nigeria \\ 3.Department of Biochemistry, Faculty of Life Sciences, University of Benin, Benin City, Nigeria \\ 4.Department of Pure and Applied Chemistry, Faculty of Pure and Applied Sciences, Ladoke Akintola \\ University of Technology, Ogbomoso, Oyo State, Nigeria
}

\begin{abstract}
Diabetes is a disease marked by elevated blood sugar levels, and the second leading cause of renal diseases and blindness worldwide. Artesunate is an antimalarial drug, that has been reported to have hypoglycemic potential, but to the best of our knowledge, much work has not been done to explore the biochemical and clinical implications of administration of artesunate on a diabetic subject. This study investigates biochemical changes in terms of oxidative status associated with oral administration of artesunate on diabetic animal model. Twenty eight male Wistar rats weighing averagely $200 \mathrm{~g}$ were divided into four groups of seven rats each, Group Acontrol, B- Diabetes only, C- Artesunate only, D- Diabetes + Artesunate. Diabetes was induced intraperitoneally, at a single dose of Alloxan $(160 \mathrm{mg} / \mathrm{kg}$ body weight $(\mathrm{bw})$. Artesunate was administered orally in aqueous solution at $2.90 \mathrm{mg} / \mathrm{kg}$ bw on day one, and at $1.45 \mathrm{mg} / \mathrm{kg}$ bw on the subsequent 7 days. Spectrophotometric technique was used for biochemical analysis in serum, kidney and liver homogenates. Aspartate amino transferase (AST) and Alanine amino transferase (ALT) activities as well as Creatinine concentration were significantly $(\mathrm{P}<0.05)$ increased in group B compared with control, while group D showed a significant $(\mathrm{P}<0.05)$ decrease compared with group $\mathrm{B}$. Total protein concentration was significantly $(\mathrm{P}<0.05)$ increased in group $\mathrm{B}$ compared with control, while group D showed an insignificant decrease compared with group B. Moreover, Superoxide dismutase(SOD) and Catalase(CAT) activities as well as Reduced glutathione (GSH) concentration were significantly $(\mathrm{P}<0.05)$ decreased in group $\mathrm{B}$ compared with control, and were restored near to the control level significantly $(\mathrm{P}<0.05)$ in group $\mathrm{D}$, compared with group $\mathrm{B}$. Malondialdehyde $(\mathrm{MDA})$ concentration was significantly $(\mathrm{P}<0.05)$ increased in group $\mathrm{B}$ compared with control, but was reversed significantly $(\mathrm{P}<0.05)$ in group D compared with group B. Artesunate ameliorates oxidative stress in diabetic rats liver and kidney, possess hypoglycemic effect, hence antioxidant and hypoglycemic effects of artesunate may be beneficial to diabetic liver and kidney.
\end{abstract}

Keywords: Artesunate, Diabetes mellitus, Hypoglycemia, Alloxan, Antioxidant.

DOI: $10.7176 /$ ALST/72-03

Publication date:March $31^{\text {st }} 2019$

\section{INTRODUCTION}

Diabetes mellitus is a leading cause of morbidity and mortality worldwide. It is a metabolic disorder of multiple etiology characterized by chronic hyperglycemia with disturbance of carbohydrate, fat, and protein metabolism which may result from defects in insulin secretion, insulin action or both (Shoback, 2011). Environmental factors, genes and pathological condition like autoimmune eradication in beta cells of the pancrease that leads to deficiency of insulin and some other abnormalities causing insulin resistance are involved in the etiology of diabetes (Okur et al., 2017). Type 1 diabetes (Insulin Dependent Diabetes Mellitus) is caused by a lack of insulin due to the destruction of insulin-producing beta cells in the pancreas. Here, the body's immune system attacks and destroys the beta cells. Type 1diabetes indicates the processes of destruction of beta-cells that may ultimately lead to diabetes mellitus in which insulin is required for survival to prevent the development of ketoacidosis, coma and death. An individual with a type 1diabetes process may be metabolically normal prior to when the disease is clinically manifest, but the process of beta-cell destruction can be detected. Presence of antiGAD usually characterize type 1 diabetes mellitus, islet cell or insulin antibodies which identify the autoimmune processes that lead to beta-cell destruction (WHO 1999). Beta cells destruction in the pancrease provokes an insulin insufficiency hence, diabetic patients with type 1 are subjected to daily insulin administration to normalize the sugar concentration present in their blood (WHO, 2016).Type 2 diabetes (Non Insulin dependent diabetes Mellitus), is the most common form of diabetes which is characterized by insulin disorder, action and insulin secretion, either of which may be the predominant feature. Both are usually present at the time that this form of diabetes is clinically manifest (WHO 1999). In type 2 diabetes, individual has relative rather than 
absolute insulin (Toma et al., 2013).It is a continuous insulin secretion defect that is based on insulin resistance as a result of body's inability to efficiently utilize insulin produced. Here, body is capable of insulin production, but becomes resistant and insulin becomes ineffective (Olokoba et al., 2012, WHO, 2016). Symptom of diabetes mellitus includes thirst, polyuria, weight loss, polyphagia, polydipsia and blurring of vision. In its most severe forms, may result to ketoacidosis or a non-ketotic hyperosmolar state which may lead to stupor, coma and, in absence of effective treatment, result to death. The effects of diabetes mellitus include long- term damage, malfunctioning and failure of various organs of the body. (Shoback, 2011)

Approximately $20 \%$ to $40 \%$ of patients having type 1 and type 2 diabetes mellitus develop diabetic kidney diseases (DKD) with a clinical syndrome characterized by persistent albuminuria $(>300 \mathrm{mg} / 24 \mathrm{~h}$ or $300 \mathrm{mg} / \mathrm{g}$ creatinine) (Rossing and Persson 2017), continuous decline in glomerular filtration rate (GFR), increase arterial blood pressure and enhanced cardiovascular morbidity and mortality (Rossing and Persson 2017). Diabetes Kidney disease remains one of the most frequent complications of diabetes, especially type 2. Kidney, in addition to pancrease, intestine, adipocytes, and liver also plays an important role in glycemic homeostasis particularly, as a result of its contribution to gluconeogenesis and glucose tubular reabsorption (Pecoits-Filho et al., 2016).Diabetes is a disease that has been associated with a series of liver diseases such as non- alcoholic liver disease, steatohepatitis as well as liver cirrhosis. Liver cirrhosis and hepatitis $\mathrm{C}$ virus (HCV) have been associated with diabetes through insulin resistance. Cryptogenic diabetes occurs due to liver cirrhosis with a complex pathophysiology, but majorly attributed to increase resistance of insulin in the liver, adipose tissue, and muscle. Patients that have impaired functioning of the liver, which also associated with insulin resistant may need increase insulin requirement while those with altered liver metabolism might require decrease insulin requirement as reported by (Azar et al., 2014). Hemochromatosis, alcoholic Cirrhosis, Non-alcoholic fatty liver disease and chronic hepatitis $\mathrm{C}(\mathrm{CHC})$ are more frequently associated with diabetes mellitus (Garcia-compean et al., 2009).

Malaria is one of the major global health problems today, with an estimated 300 to 500 million clinical cases usually occurring annually, it is a public health problem in more than $40 \%$ of the world population (Date et al., 2007). It remains one of the leading causes of mobidity and mortality in the tropics. It is caused by infection of a single-celled parasite called Plasmodium. Malaria in human beings is caused by four Plasmodium spp, namely, Plasmodium falciparum, P.vivax, P.ovale, and P. malariae. The most severe infection and symptoms is associated with Plasmodium falciparum (Saifi et al., 2013). The antimalarial in common use nowadays come from following classes of compounds namely, the quinolones(Chloroquine, quinine, mefloquine, amodiaquine, primaquine). The antifolates (Pyrimethamine, proguanil and sulfadoxin), the artmisinin derivatives (artemisinin, artesunate, artemeter, arteether) and lastly, hydroxynaphthaquinones (atovaquine) (Saifi et al., 2013).

Artemisinin, also called qinghaosu in china and its derivatives (artesunate, artemeter, arteether) have been well used in Southeast asia, africa and china where a high level of resistance to the majority of the quinolinecontaining and antifolate drugs is recorded (Meshnick et al., 1996). Artemisinin-type compounds currently used are either natural extract of artemisinin itself or its semi-synthetic derivatives (dihydroartemisinin, artesunate and artemeter). They achieve higher reduction rate of parasitaemia per cycle than any of the other drugs known to date as reported by (White, 1997, WHO, 2016.). Artemisinin remains the most potent compound used as antimalarial drug (WHO, 2014).In uncomplicated falciparum malaria, artemisinin based combination therapy (ACT) are mostly use as the first line of treatment (Hyde, 2007). Artemisinin or its derivatives drugs once administered, it is rapidly hydrolysed to biologically active metabolite called dihydroartemisinin. Artemisinin structure tends to be unusual and its activity is believed to be dependent on presence of the endoperoxide bond as molecule without it has no antimalarial activity (Brossi et al., 1988). Endoperoxidase bond may interact with heme or iron and latter decompose into free radicals (Meshnick et al., 1993,1996, Paitayatat et al., 1997), this process in non-reversible unlike many redox reactions, The free radicals formed can form a covalent bound with parasite or heme protein (Yang et al., 1993, 1994). Artemisinin also has been shown to bind to 6 specific P.falciparum proteins, which one of the proteins is a member of the translationally controlled tumor protein family but the exact effect of this protein alkylation of the parasite is yet to be determined (Saifi et al., 2013).

Artesunate was reported to be metabolized by cytochrome P450 while this same enzyme system has been implicated in diabetes etiology (Vahabzadeh et al., 2014, Ericsson et al., 2014, Guengerich, 2008). Artesunate has been reported to have hypoglycemic effect (Salman et al., 2017) but hypoglycemic effect is far less compared to that of quinine (David et al., 2011). This study investigates biochemical changes associated with oral administration of artesunate on diabetic animal model, specifically, to investigate oxidative status of diabetic rats administered artesunate. Medicinal claims of a synthetic drug might not be too significant until suitable bioassays are employed to validate their medicinal claims.

\subsection{MATERIALS AND METHODS}

\subsection{Chemical and Reagents}

All the reagents and chemicals used for this study were of analytical grades. They were purchased from Sigmal 
Aldrich company Louis, U.S.A. and Randox Laboratory limited Ardmore Diamond road, Crumlin Uk. Artesunate (ARTs) (50mg) was purchased from Tuyil Pharmaceutical Company, Ilorin, Kwara state, Nigeria.

\subsection{Experimental Animal}

Twenty eight male Wistar rats weighing averagely $200 \mathrm{~g}$ were purchased from a reliable source. They were housed in a cage under standard laboratory condition of 12 hours light and 12 hours dark period. Acclimatization to laboratory condition was done for 2 weeks before the commencement of the experiment. All the procedures involving the use of laboratory animal were in accordance to the Institute Animal Ethics Committee regulation approved by the committee for the purpose of control and supervision of Experiments on Animals (CPCSEA).

\subsection{Experimental Design}

The rats were randomly divided into four groups of seven rats per group and treated for eight days after $72 \mathrm{hours}$ of alloxan induction..

Group A (control): Rats received standard rat pellet and distilled water only ad libitum.

Group B (Diabetes only): Rats were induced diabetes with $160 \mathrm{mg} / \mathrm{kg}$ body weight (bw) Alloxan already dissolved in $0.9 \%$ normal saline and fed with standard rat pellet and distilled water ad libitum.

Group C (Artesunate only): Rats were dosed Artesunate only at $2.90 \mathrm{mg} / \mathrm{kg}$ bw on first day and at $1.45 \mathrm{mg} / \mathrm{kg} \mathrm{bw}$ for the subsequent 7 days.

Group D (Diabetes + Artesunate) : Rats were induced diabetes followed by $2.90 \mathrm{mg} / \mathrm{kg}$ bw of Artesunate on first day, and $1.45 \mathrm{mg} / \mathrm{kg}$ for subsequent 7 days.

\subsection{Diabetes Induction}

Fourteen Albino rats in group B (Diabetes only) and D (Diab.+Artesunate) were fasted overnight and injected with Alloxan already dissolved in $0.9 \%$ normal saline intraperitoneally at a single dose of $160 \mathrm{mg} / \mathrm{kg}$ body weight (Ashok et al., 2007). The diabetes states of the rats were ascertained by measuring their blood sugar levels after 72 hours using a glucometer.

\subsection{Administration of Artesunate}

The administration of Artesunate commenced 72hours after diabetes induction. Rats in group C (Artesunate only) and group D (Diab.+Artesunate) were administered Artesunate orally at $2.9 \mathrm{mg} / \mathrm{kg}$ bw on first day and $1.45 \mathrm{mg} / \mathrm{kg}$ bw on the subsequent 7days(Salman et al., 2017). The dosage was chosen to mimic that of human.

\subsection{Sample collection and Preparation}

Experimental rats were fasted overnight and weighed before sacrifice was done by cervical dislocation, animals were dissected for sample collection.

\subsubsection{Collection and preparation of blood serum}

The blood samples were carefully collected by cardiac puncture using sterile needle and syringe, drained into sterilized sample bottles and left for 30 munites, centrifuged at $3000 \mathrm{rpm}$ for 10 minutes. The serum was picked to sterilized sample bottles for biochemical analysis.

\subsubsection{Collection and preparation of Tissue}

The renal and liver tissues of the rats were quickly removed after sacrifice, weighed, washed repeatedly in chilled $1.15 \mathrm{M} \mathrm{Kcl}$ and placed in clean sample bottle. Renal and hepatic tissues were homogenized with sucrose phosphate buffer using homogenizer.

\subsection{Determination of Serum Alanine Amino Transferase (ALT) and Aspartate amino Transferases (AST) Activities}

The ALT activity was measured by monitoring the concentration of the pyruvatehydrazon formed with 2,4 dinitrophenyhydrazine as specified by Reitman and Frankel 1951. AST activity was determined by monitoring the concentration of oxaloacetate hydrazine formed with 2,4-dinitrophenylhydrazine as specified by assay kit.

\subsection{Determination of serum Total protein concentration}

Serum total protein concentration was determined based on the method described by Folin-lowry (Lowry et al., 1951). Protein reacts with follin-ciocalteau reagent to give a blue coloured complex that absorbed at wavelength of $500 \mathrm{~nm}$

\subsection{Determination of lipid peroxidation}

Estimation of lipid peroxidation was based on the reaction of Malondialdehyde (MDA) with Thiobarbituric acid (TBA) forming MDA-TBAR adduct that absorbed strongly at 532nm, as described by Varsney and Kale(1990). 


\subsection{Determination of Superoxide Dismutase (SOD) and Catalase (CAT) activities}

Superoxide dismutase (SOD) activity was determined by method of Misra and Fridovich (1972). SOD inhibits auto oxidation of epinephrine to adrenochrome and absorbance read at $480 \mathrm{~nm}$. Catalase activity was measured according to the method of Aebi (1983). The rate of decomposition of $\mathrm{H}_{2} \mathrm{O}_{2}$ was measured spectrophotometrically from change in absorbance at $240 \mathrm{~nm}$.

\subsection{Determination of Reduced glutathione (GSH) Concentration}

Reduced glutathione (GSH) estimation was based on the development of relatively stable yellow colour that absorbed at $412 \mathrm{~nm}$ when 5,5, dithiobis-2-nitrobenzoic acid is added to sulphydryl compounds as described by Moron et al., 1979.

\subsection{Determination of serum Creatinine concentration}

Serum creatinine level was determined by the method specified in the assay kit. Creatinine in alkaline solution reacts with Picric acid to form a coloured complex that was measured spectrophotometrically. The amount of the complex formed was directly proportional to the creatinine concentration.

\subsection{Statistical Analysis}

All data were presented as Mean \pm Standard error of Mean (SEM). Statistical analysis was carried out using Graphpad prism 5 Software. One way Analysis of Variance (ANOVA) was used for the comparison of relative expression levels for different groups, this was followed by Turkey Post hoc Test.

\subsection{Results}

3.1 Fasting blood sugar concentration after 72hours of alloxan induction(A) and fasting blood sugar concentration after treatment $(\mathrm{B})$.

(A)

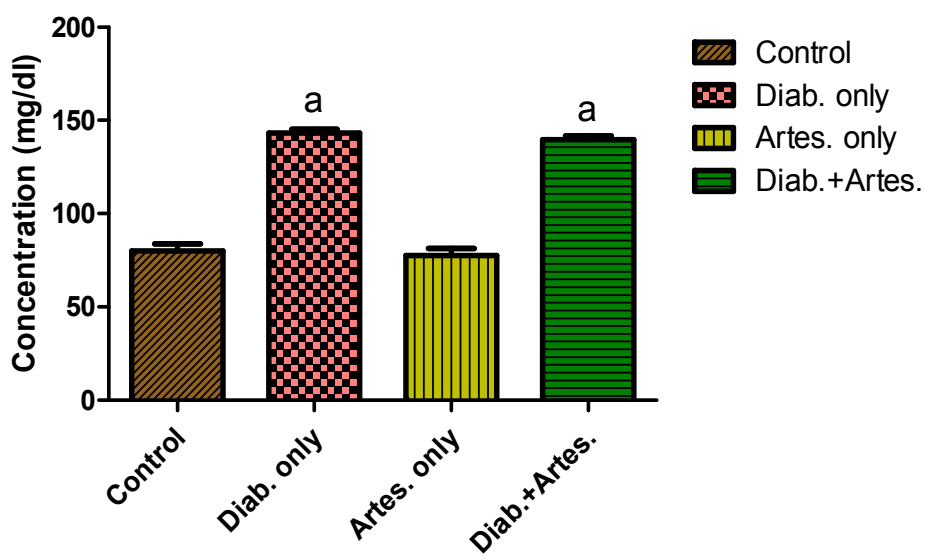

Fasting bloodsugar concentration after 72 hours of alloxan induction before artesunate treatment

Level of significance was taken at $(\mathrm{P}<0.05)$ for six rats per group

' $\mathbf{a}$ ' represents significant increase when compared with control and Artesunate only group.

(B) 


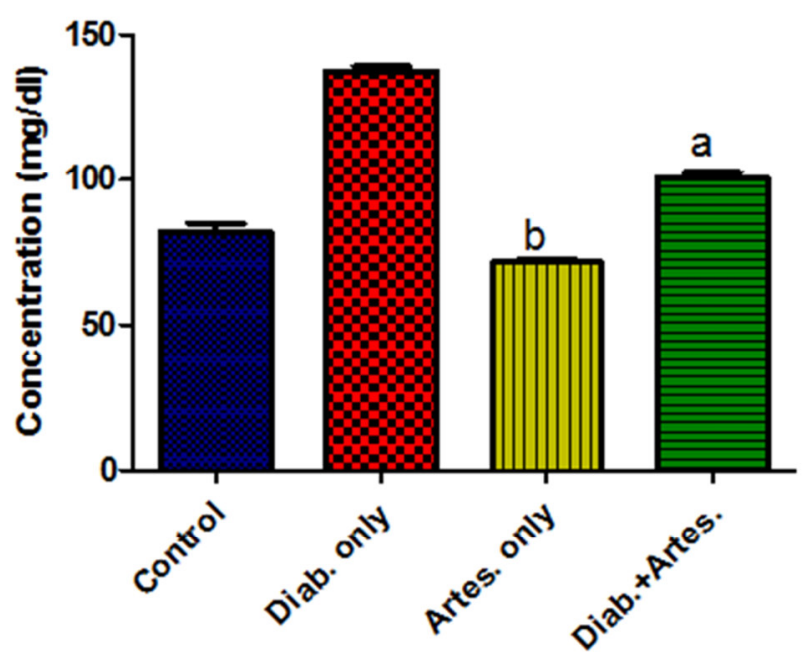

\section{Fasting blood sugar concentration after Treatment}

Level of significance was taken at $(\mathrm{P}<0.05)$ for six rats per group

' $\mathrm{a}$ ' represents significant decrease when compared with Diabetes only group

'b' represents significant decrease when compared with control

\subsection{Alanine amino transferase (ALT) activity.}

There is a significant $(\mathrm{P}<0.05)$ increase in ALT activity in group B (Diabetes only) when compared with group A (Control) and other groups. An insignificant decrease was observed in group C (Artesunate only) when compared with group A (control). A significant $(\mathrm{P}<0.05)$ decrease was observed in group D (Diab. + Artesunate) when compared with group B (Diabetes only).

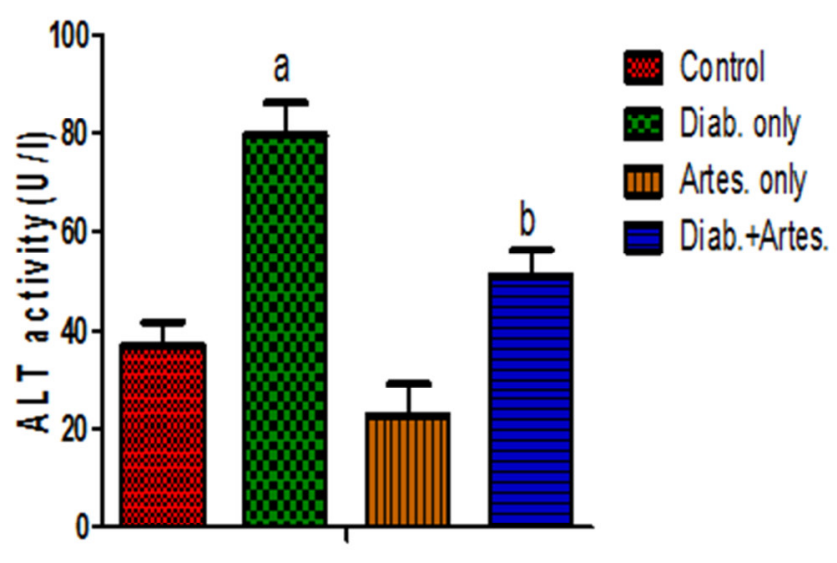

\section{Alanine amino transferase activity in serum of various treatment groups}

Level of significance was taken at $(\mathrm{P}<0.05)$ for six rats per group

' $\mathrm{a}$ ' represents significant increase when compared with control and other groups

'b' represents significant decrease when compared with Diabetes only.

\subsection{Aspartate amino transferase (AST) activity}

Aspartate amino transferase (AST) activity in group B (Diabetes only) was significantly $(\mathrm{P}<0.05)$ increased when compared with control and other groups. An insignificant decrease is AST activity was observed in group $\mathrm{C}$ (Artesunate only) when compared with group A (control), while a significant $(\mathrm{P}<0.05)$ decrease was observed in group D (Diab.+Artesunate) when compared with group B (Diabetes only). 


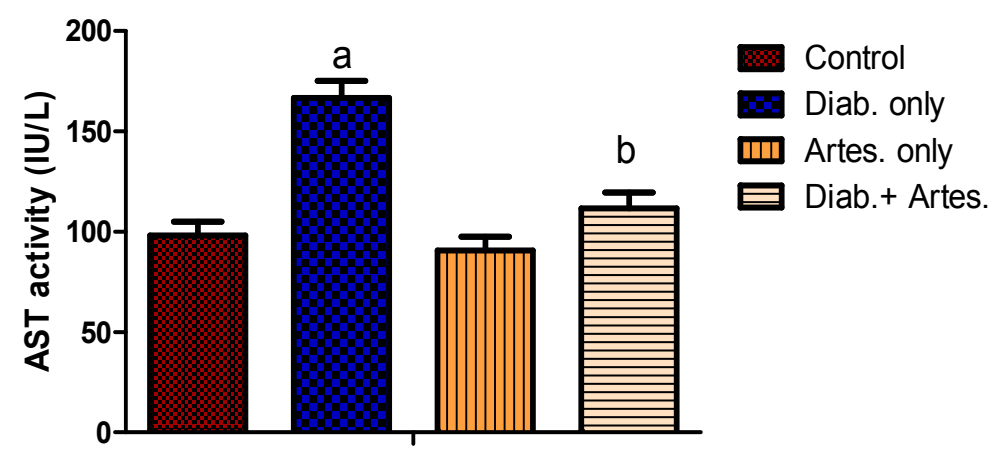

Aspartate amino transferase activity in serum of various treatment groups

Level of significance was taken at $(\mathrm{P}<0.05)$ for six rats per group

' $\mathrm{a}$ ' represents significant increase when compared with control and other groups.

'b' represents significant decrease when compared with Diabetes only

\subsection{Total protein Concentration.}

Serum total protein concentration was significantly $(\mathrm{P}<0.05)$ increased in group B (Diabetes only) when compared with control group. An insignificant increase was observed in group C (Artesunate only) when compared with control. Group D (Diab.+Artesunate) showed an insignificant decrease in total protein compared with group B (Diabetes only).

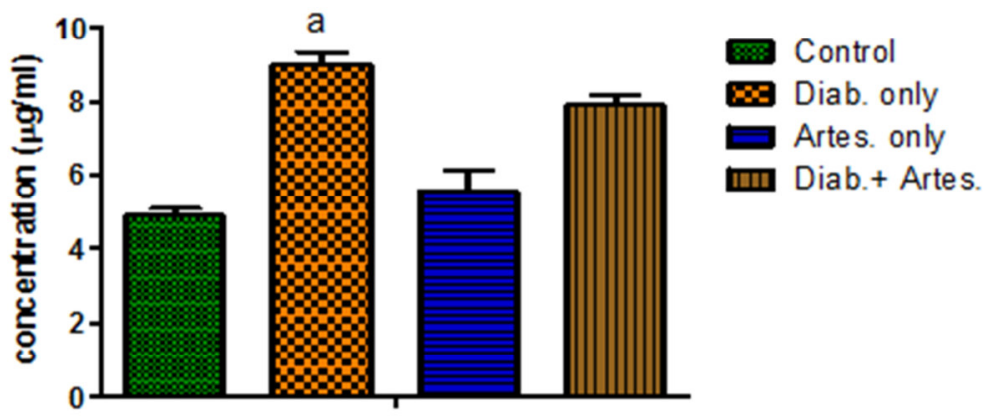

Total Protein concentration in serum of various treatment groups

Level of significance was taken at $(\mathrm{P}<0.05)$ for six rats per group

' $\mathbf{a}$ ' represents significant increase in diabetes only group when compared with control and artesunate only group

\subsection{Creatinine concentration}

Serum creatinine concentration in group B (Diabetes only) was significantly $(\mathrm{P}<0.05)$ increased when compared with group A (control) and other groups. Group C (Artesunate only) showed an insignificant decrease when compared with control. A significant $(\mathrm{P}<0.05)$ decrease was also observed in group D (Diab.+Artesunate) when compared with group B (Diabetes only). 


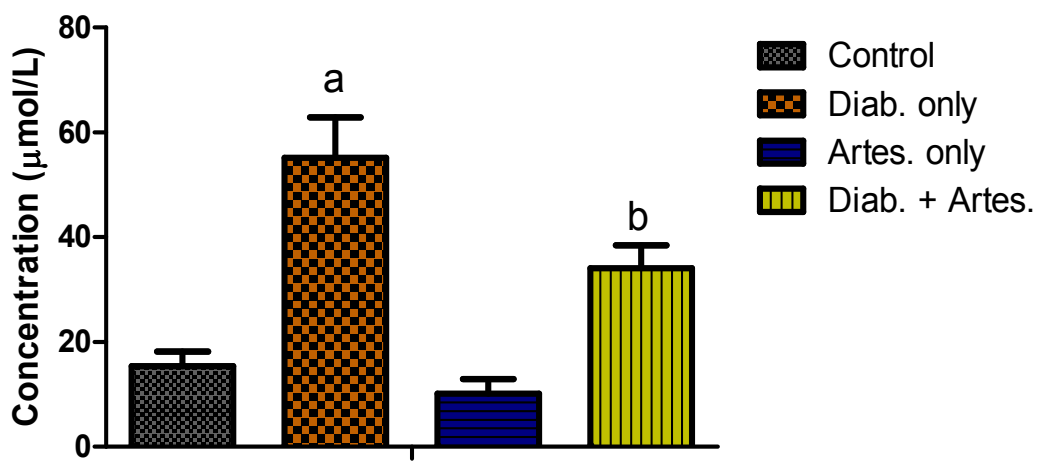

\section{Creatinine concentration in serum of various treatment groups}

Level of significance was taken at $(\mathrm{P}<0.05)$ for six rats per group

' $\mathbf{a}$ ' represents significant increase when compared with control and other groups.

'b' represents significant decrease when compared with diabetes only

\subsection{Measurement of lipid peroxidation.}

Malondialdehyde concentration was significantly $(\mathrm{P}<0.05)$ increased in group B (Diabetes only) when compared with control and other groups. Group $C$ (Artesunate only) showed an insignificant increase in concentration of MDA when compared with control, while group D (Diab.+Artesunate) showed significant $(\mathrm{P}<$ $0.05)$ decrease in MDA compared with group B (Diabetes only).

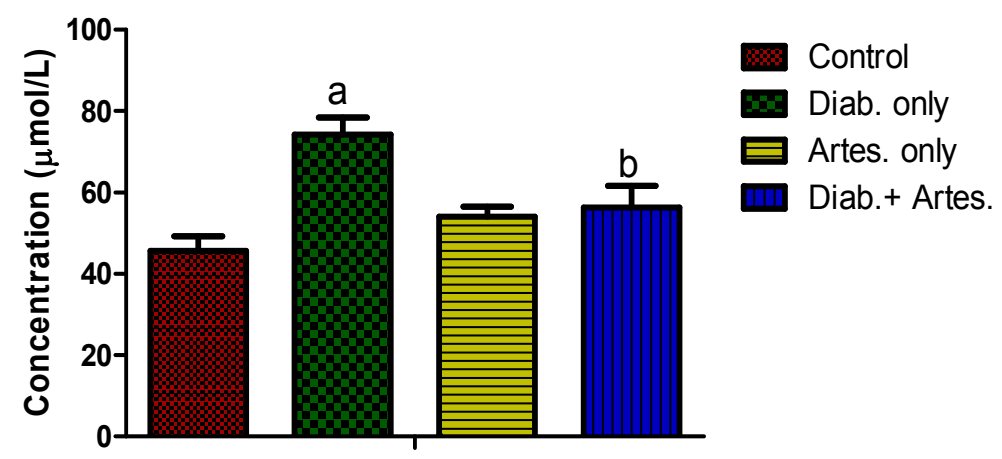

\section{Malondialdehyde(MDA) concentration in Kidney of various treatment groups}

Level of significance was taken at $(\mathrm{P}<0.05)$ for six rats per group

' $\mathrm{a}$ ' represents significant increase when compared with control and other groups.

' $b$ ' represents significant decrease when compared with diabetes only

\subsection{Superoxide dismutase (SOD) and Catalase (CAT) activities in the kidney}

Superoxide dismutase (SOD) (A) and Catalase (CAT) (B) activities were significantly $(\mathrm{P}<0.05)$ decreased in group B (Diabetes only) when compared with control, group C (Artesunate only) showed a significant increase in activities of SOD and Catalase compared with group A (control), while a significant $(\mathrm{P}<0.05)$ increase was observed in group D (Diab.+Artesunate) when compared with group B (Diabetes only). 
(A)

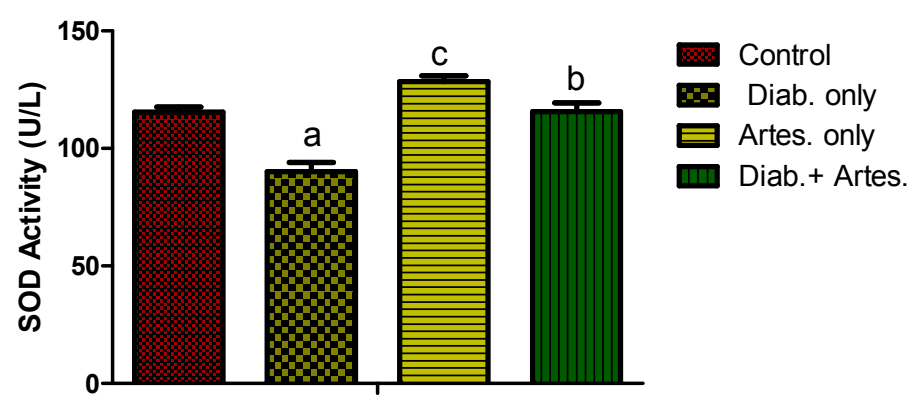

Superoxide dismutase(SOD) Activity in Kidney of various treatment groups

Level of significance was taken at $(\mathrm{P}<0.05)$ for six rats per group

' $\mathbf{a}$ ' represents significant decrease when compared with control and other groups.

'b' represents significant increase when compared with Diabetes only

'c' represents significant increase when compared with control and diabetes only group

(B)

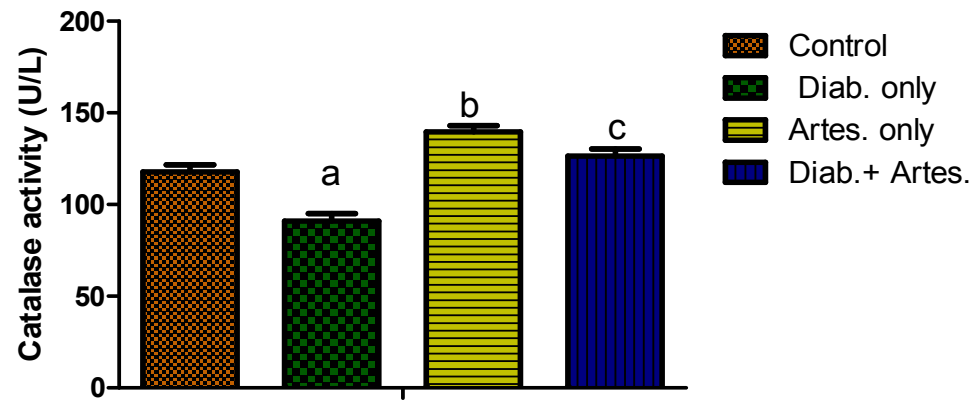

catalase activity in kidney of various treatment groups

Level of significance was taken at $(\mathrm{P}<0.05)$ for six rats per group

' $\mathbf{a}$ ' represents significant decrease when compared with control and other groups.

' $b$ ' represents significant increase when compared with control and diabetes only.

'c' represents significant increase when compared with control and diabetes only group

\subsection{Reduced glutathione (GSH) concentration}

Reduced glutathione $(\mathrm{GSH})$ concentration was significantly $(\mathrm{P}<0.05)$ decreased in group B (Diabetes only) when compared with control and other groups, group $\mathrm{C}$ (Artesunate only) showed a significant $(\mathrm{P}<0.05)$ increase in GSH concentration when compared with control, group D (Diab.+Artesunate) also, when compared with group B (Diabetes only) showed a significant $(\mathrm{P}<0.05)$ increase in GSH concentration.

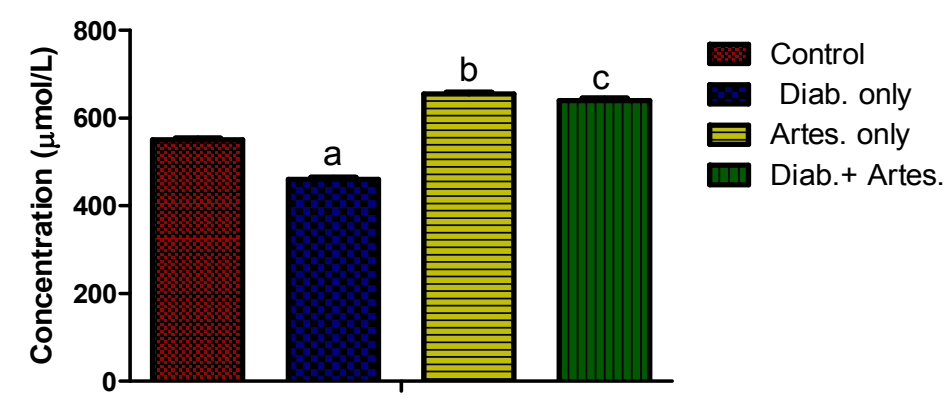

\section{Reduced Glutathione (GSH) concentration in kidney of various treatment groups}

Level of significance was taken at $(\mathrm{P}<0.05)$ for six rats per group

' $\mathbf{a}$ ' represents significant decrease when compared with control and other groups.

' $\mathbf{b}$ ' represents significant increase when compared with control and diabetes only

'c' represents significant increase when compared with control and diabetes only group 


\subsection{Catalase (CAT) and Superoxide dismutase (SOD) activities in the Liver}

Catalase (CAT) (A) and Superoxide dismutase (SOD) (B) activities were significantly $(\mathrm{P}<0.05)$ decreased in group B (Diabetes only) when compared with control, group C (Artesunate only) showed an insignificant increase in activities of SOD and Catalase compared with control, while a significant $(\mathrm{P}<0.05)$ increase was observed in group D (Diab.+Artesunate) when compared with group B (Diabetes only).

(A)

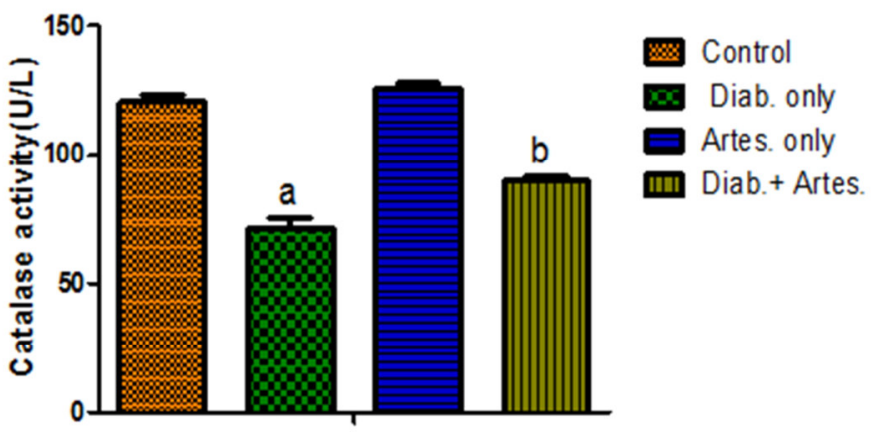

\section{Catalase activity in the Liver of various treatment group}

Level of significance was taken at $(\mathrm{P}<0.05)$ for six rats per group

' $a$ ' represents significant decrease when compared with control and other groups.

'b' represents significant increase when compared with Diabetes only

(B)

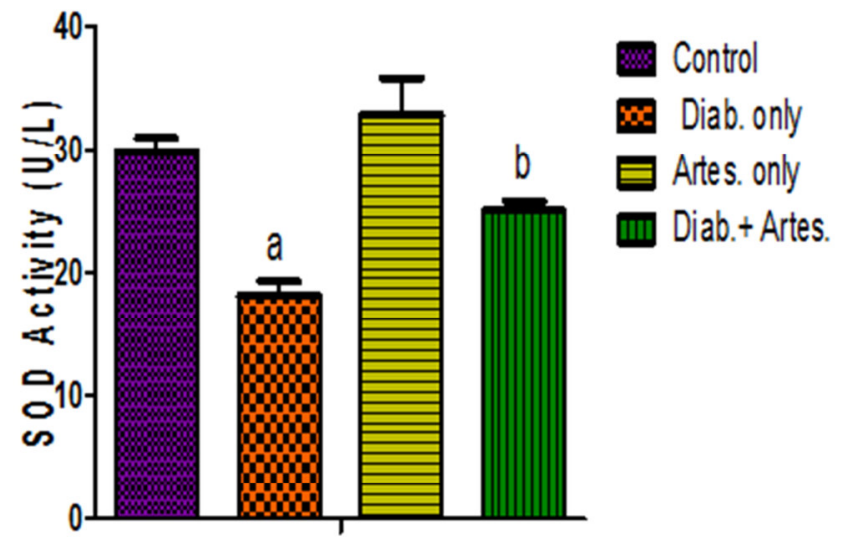

\section{Superoxide dismutase activity in liver of various treatment groups}

Level of significance was taken at $(\mathrm{P}<0.05)$ for six rats per group

' $\mathbf{a}$ ' represents significant decrease when compared with control and other groups.

'b' represents significant increase when compared with Diabetes only

\section{DISCUSSION}

Glycemic homeostasis refers to glucose balance or control within circulation in living organisms. It is normally and largely compromised in diabetes state. When the compromise is worsen, it leads to several complications including retinopathy, nephropathy and neuropathy which are all collectively referred to as diabetic complications and these are the principal factors in morbidity and mortality often associated with diabetes (Ighodaro et al., 2018).Alloxan and streptozotozin are the most popular diabetogenic agents used for assessing the antidiabetic or hypoglycemic capacity of test compounds, Notably, alloxan is far less expensive and much more readily available than streptozotozin (Ighodaro et al., 2018). The Cytotoxic action of Alloxan as a diabetogenic agent is mediated by Reactive Oxygen Species(ROS)(Szkudelski 2001), Alloxan, a toxic glucose analogue accumulates in pancreatic beta cells via the action of glucose transporter referred to as GLUT2 (Lenzen, 2008). In the presence of intracellular thiol like glutathione, Alloxan generates ROS in a cyclic redox reaction with its reduction product called dialuric acid. The process of autoxidation of dialuric acid leads to generation of superoxide radicals, hydrogen Peroxide and finally, hydroxyl radicals. These generated hydroxyl radicals are ultimately responsible for the death of beta cells which have low antioxidative defense capacity resulting in the state of Insulin-dependent alloxan diabetes (Lenzen, 2008). In figure 3.1, Blood sugar level after 
72hours of Alloxan induction before artesunate administration showed a significant $(\mathrm{P}<0.05)$ increase in Group B (Diabetes only) and Group D (Diab. + Artes.) when compared with group A (control) and group C (artesunate only), this showed that, beta cell destruction in pancrease has been occasioned by the action of reactive oxygen species generated by alloxan metabolic intermediates. Moreover, after the treatment, group D (Diab.+artes.) showed a significant $(\mathrm{P}<0.05)$ decrease in blood sugar concentration restored near to the control comparably with group B (Diabetes only). This suggests hypoglycemic potential of artesunate and its possible antioxidant ability.

The aminotransferases are the most frequently utilized and specific indicators of hepatocellular necrosis. These enzymes, aspartate aminotransferase (AST) and alanine amino transferase (ALT) catalyze the transfer of the $\alpha$-amino acids of aspartate and alanine respectively to the keto-group of $\alpha$-ketoglutaric acid. Serum, AST and ALT are the most sensitive biomarkers used in the diagnosis of liver diseases (Pari and Murugan, 2004). During hepatocellular damage, varieties of enzymes normally located in the cytosol are released into the blood flow. Their quantification in plasma is useful biomarkers of the extent and type of hepatocellular damage (Pari and Murugan, 2004).Serum ALT and AST are liver enzymes, that leak out into general circulation when there is damage to the liver cells. Both AST and ALT have been reported as useful predictors of liver pathology (Anderson et al., 2000). In figure 3.2 and 3.3 ALT and AST activities were significantly $(\mathrm{P}<0.05)$ increased in group B (Diabetes only) when compared with control and other groups. There was an insignificant decrease in AST and ALT activities in group C (Artesunate only) when compared with group A (control), administration of artesunate in group D (Diab.+Artesunate) occasioned a significant $(\mathrm{P}<0.05)$ decrease in serum activities of these enzymes compared to group B (Diabetes only). Artesunate or its metabolites might have exhibited hepatoprotective effects that led to decrease in serum ALT and AST activities.

Proteins are constituents of muscle, enzyme, hormone, and other key functional and structural entities in the body. Elevated levels of protein are found in dehydration while reductions are seen mainly in malnutrition, impaired protein synthesis, protein losses, and excessive protein breakdown (Doumas and Bayse, 1981). In figure 3.4, total protein concentration was significantly $(\mathrm{P}<0.05)$ increased in group B (Diabetes only) when compared with control. Group D (Diab.+Artesunate) showed an insignificant decrease in serum total protein when compared with group B (Diabetes only), while comparison between group C (Artesunate only) and control was not statistically significant. Dehydration that occurred as a result of diabetes complication might have resulted in elevated level of serum total protein in group B (Diabetes only) while slight reduction in serum total protein might be traced to effect of artesunate or its metabolite.

Serum creatinine is an important indicator of renal function. It is synthesized in the kidney from amino acids Arginine, glycine and methionine. An elevated blood creatinine level is observed with marked damaged to functioning nephrons (Gross et al., 2005). In figure 3.5, alloxan occasioned a significant $(\mathrm{P}<0.05)$ increase in serum creatinine in group B (Diabetes only) when compared with control. There was an insignificant decrease in group C (Artesunate only) compared with control, while group D (Diab.+Artesunate) showed significant $(\mathrm{P}<$ 0.05) decrease in creatinine concentration when compared with group B (Diabetes only). Interestingly, this is consistent with the work of Chiagoziem et al., (2012). This revealed that, artesunate might possess properties that ameliorate oxidative stress in the Kidney.

The constituents of cell biomembranes are liable to free radical and active oxygen damage. The actions of these free radicals trigger cell damage by covalently binding with cellular macromolecules and formation of lipid peroxidation (Ajay et al., 2010) which are implicated in the processes such as carcinogenesis, inflammation and aging (Ames et al., 1993).Free radicals produced from oxidative stress have potential to react quickly with lipid in the body to form lipid peroxide (LPO) (Rukkumani et al., 2004). Result obtained in figure 3.6 showed a significant $(\mathrm{P}<0.05)$ increase in MDA concentration in group $\mathrm{B}$ (Diabetes only) when compared with control and other groups. Group C (Artesunate only) showed an insignificant increase in MDA concentration when compared with control while group D (Diab.+Artesunate) showed significant decrease when compared with group B (Diabetes only). This reflects that, artesunate administration "in diabetes state" may stabilize or protects biomembranes in renal tissue.

Superoxide dismutase (SOD) and Catalases (CAT) are enzymatic antioxidants. SODs are class of closely related enzymes catalyzing the breakdown of superoxide anion to oxygen and Hydrogen peroxide (Zelko et al., 2002). They are present in almost all aerobic cells and in extracellular fluid (Johnson et al., 2005). Catalase enzyme catalyzes conversion of hydrogen peroxide to water and oxygen using iron or Manganese co factor. Tissues are protected from oxidative stress with increase catalase activity while on reduction are under attack of oxidative stress (Chelikani et al., 2004). In figures 3.7(A and B), SOD and Catalase activities were significantly $(\mathrm{P}<0.05)$ decreased in group $\mathrm{B}$ (Diabetes only) when compared with control. Moreover, a significant $(\mathrm{P}<0.05)$ increase was observed in group C (Artesunate only) when compared with control and group B (diabetes only), furthermore, a significant $(\mathrm{P}<0.05)$ increase was observed in group $\mathrm{D}$ (Diab.+Artesunate) when compared with group B (Diabetes only). Also, in figure 3.9 (A and B), liver catalase and superoxide dismutase activities were significantly $(\mathrm{P}<0.05)$ decreased in group B (Diabetes only) when compared with control and other groups, 
while these enzymes activities were restored significantly $(\mathrm{P}<0.05)$ in group $\mathrm{D}$ (Diab.+ Artesunate) when compared with group B (Diabetes only). An insignificant increase was observed in group C (Artesunate only) when compared with group (A) control. Artesunate or its metabolites might have elicited pathways that led to elevation of these antioxidant enzymes in renal and hepatic tissues.

Reduced glutathione (GSH) serves as non-enzymatic antioxidant biological molecule in the body tissue. It functions to remove non radical compounds like hydrogen peroxide, Alkoxyl radical, and superoxide anion from tissue (Townsend et al., 2003). In figure 3.8, alloxan occasioned a significant $(\mathrm{P}<0.05)$ decreased in GSH concentration in group B (Diabetes only) when compared with control and other groups, Group C (Artesunate only), showed a significant $(\mathrm{P}<0.05)$ increase in GSH concentration when compared with control. Moreover, group D (Diab.+Artesunate) showed significant $(\mathrm{P}<0.05)$ increase when compared with group B (Diabetes only). Artesunate might have elicited pathways that enhances reduced glutathione concentration in renal tissue.

Conclusion: from the result of this present work, artesunate ameliorates oxidative stress in diabetic rats Liver and Kidney hence, antioxidant effect of artesunate may be beneficial to diabetic Kidney and liver. Moreover, diabetic patients that have malaria may opt for artesunate to benefit themselves for its antioxidant and hypoglycemic potential.

Acknowledgement: We acknowledge the effort of the scientists at the university Central Research Laboratoty at Ladoke Akintola University of Technology, Ogbomoso, for allowing free access to research equipments for this research work.

Conflict of Interest: There is no conflict of interests among authors in this work.

\section{References}

Aebi ,H.,(1983).Catalase: in method of enzymatic analysis,Bergmeyer,H.U:J Bergmeyer, M. grassl, D.W.moss, H,Fritz IR.F. Massageff and M.Qellench (Eds.) $3^{\text {rd }}$ Edn, verlag chemie, weinheim, Germany ISBN 13 : 9783527260430,PP: $273-277$.

Ajay, K.G., c. Havagiray, K.O. Sujata and M. Neelam, (2010). Antioxidant activity of Chanomile recutita Capitula methanolic extracts against CCl4-induced liver injury in Rats.J. Pharmacol., Toxicol., 5: 473-479.

Alemayehu Toma, Eyasu Makonnen, Getnet Yimer. Role of zinc in diabetes mellitus, oxidative stress and other human healthy: a review article. American Journal of Research Communication, 2013, 1(11): 411-426\} www.usa-journals.com, ISSN: 2325-4076.

Ames, B.N., M.K. Shigenaga and T.M. Hagen, 1993. Oxidants, antioxidants and the degenerative diseases of aging. Proc. Natl. Acad. Sci., 90:7915-7922.

Anderson FH, Zeng L., Rock NR, and Yoshida EM .(2000) 'An assessment of the clinical utility of serum ALT and AST in chronic hepatitis C.July :18 (1):63 - 71

Ashok D.,Chongale, Shrimant N. Panaskar, Pradeep M., Gurao and Akalpita U. Arvindekar,(2007): optimization of alloxan dose is essential to induced stable diabetes for prolonged period.Asian Journal of Biochemistry 2.40.2.408. DOI: $10.3923 /$ cyb. 2007.402.408

Chelikani P., Fita I, Loewen P. (2004). 'Diversity of structures and properties among catalases' cell Moi Life. Sci 61 (2): 192-208.

Chiagoziem A., Otuechere, Gloria Edewor,Olufemi Ezekiel Kale, Martins Ekor.(2012). 'Subacute therapeutic Dosing of artemether - lumefantrine and Artesunate - Amodiaquine combination preserves plasma Cholesterol, Renal Antioxidant status, and organ weight in rats" Article ID 257986.

David sin Clair 1: Sarah done gan 1,Racheal I sba 1, David G Lallo .( 2011) 'Artesunate versus quinine in study of severe malaria 1'.

Date AA, Joshi MD, Patravale VB. (2007): Parasitic diseaeses: Liposome and polymeric nanoparticles versus lipid nanoparticles Adv. Drug Deliv. Rev. 2007: 59:505-21.

Ericsson T., Sundell J., Torkelssson A., Hoffmann Kj, Ashton M., (2004): Effects of artemisinin antimalarias on cytochrome P450 enzymes invitro using recombinant enzymes and human liver microsomes. Potential implication therapies. PMID: 24400699, DOI:10.3109/00498254.2013.158788.

Frederick Persson and Peter Rossing (2017): Diagnosis of Diabetic kidney disease: State of the art and future perspective. International society of Nephrology. Elsevier inc. http/Doi.org/10.1016/j.kisu.2017.10.003.

Garcia-Compean D, Jaquez-Quintana JO, Gonzalez-Gonzalez JA, Maldona do-Garza H (2009) : Liver Cirrhosis and diabetes: Risk factors, pathophysiology, clinical implications and management. World J Gastroenterol 2009:15(3):280availablefromURL:http://www.wjgenet.com/1007.9327/15/280.hsp.DOI:htpp://dx.doi.org/1 0.3748 /wjg.15.280.

Gross Jl,de Azevedo MJ,Silveino Sp,Canani LH., Caramori ML.,Zelmanovitz T.,(2005) 'Diabetic nephropathy diagnosis, prevention and treatment diabetes care 28(1):164.176.

Guengerich FP, Kim DH, Iwasaki M. (1991); Role of human cytochrome P-450 IIE1 in the oxidation of many low molecular weight cancer suspects. Chem Res Toxicol. 4:168-179.

Hala Ahmadieh, and Sami T. Azar (2014) : Liver diseases and diabetes: Association, pathophysiology and 
management. Diabetes research and clinical practice. https:// doi.org/10.1016/j. diabres..01.003.

Hyde JE. (2007): Drug resistant malaria an Insight. FEBSJ.2007:274:14688-98.

Ighodaro O.M, Adeosun A.M., Akinloye O.A.,(2018):Alloxan -Induced diabetes, a common model for evaluating the glycemic-control potential of therapeautic compounds and plants extract in experimental studies. Science Direct http://doi.org/10.1016/j.medici.2018.02.001.

Johnson F., Giulivic (2005). ' Superoxide dismutases and their impact upon human health' mol. Aspects Med 26 (4-5): 340-52.

Jollow D.J., Thogeirsson S.S, Potter W.Z., Hashimoto M. and Mitchell J.R., (1974). Acetaminophen-induced hepatic necrosis. VI. Metabolic disposition of toxic and nontoxic doses of acetaminophen. Pharmacology, 12: $251-271$.

Lenzen S.,(2008): The mechanism of Alloxan- and Streptozotocin-induced diabetes. Diabetelogia,51 (2) , pp. 216-226.

Lowry O.H, Rosebrough N.J, Farr A.L and Randall R.J. (1951). Protein measurement with the folin phenol reagent. J. Biol. Chem. 193(1):265-75.

Meshnick SR., Yang YZ,Lima V, Kuypers F, Kamchonwongpaisan S.,Yuthafong Y., (1993): Iron -dependent free radical generation from the antimalarial agent artemisinin(qinghaosu). Antimicrob. Agent chemoter.37:1108-1114

Mehmet Evren Okur, Loannis D. Karantas, Panorala I. Siafaka. (2017): Diabetes Mellitus. A review on pathophysiology, Current status of oral medications and future perspectives. Act a Pharm. Sci. Vol 55 No : 1. 2017 DOI: $10.23893 / 1307-2080$.APS.0555.

Meshnick S., Taylor T.E, Kamchonwongpaisan s. (1996). Artemisinin and antimalarials endoperoxidases: from herbal remedy to targeted chemotherapy. Microbio. Rev. 60:301-315.

Misra HP, and Fridovich I. (1972). The role of super oxide anion in the auto oxidation of epinephrine and a simple assay for super oxide dismutase. J. Biol. Chem. 247: 3170-3175.

Olokoba, A.B: Obateni, O.A. and Olokoba, L.B. (2012): Type 2 Diabetes Mellitus: A review of current trends.Oman Med. J. 2012, 27 (4), 269-273.

Paitayatat S.Tarnchompoo B., Thebtaranonth Y, Yuthavong Y (1997). Correlation of antimalarial activity of artemisinin derivatives with binding affinity with ferroprotoporphyrin ix. J. Med. Chem.40:633-638.

Pari L, Murugan P (2004). Protective role of tetrahydrocurcumin against erythromycin estolate- induced hepatotoxicity. Pharmacol. Res., 49(5):481-486.

Roberto Pecoits-Filho, Hugo Abensur, Carolina C.R. Betonico, Allison Diego Machado, Erika B. Parente, Marcia Queiroz, Joao Eduardo Nunes Salles, Silvia Titan and Sergio Vencio (2016): Interactions between kidney disease and diabetes: Dangerous liasions. Diabetology and metabolic syndrome, doi.org/10.11861513098-016-0159.z.

Rukkumani, R., Aruna, K., Varma, PS., Rajasekaran, KN. and Meno, VP.( 2004): Comparative effects of curcumin and an analog of curcumin and PUFA induced oxidative stress.JPharm Pharm Sci.,; 7: 274-83.

Saifi Muheet Alam, Tanveer Beg, Abdul Halim harrath, Fahad Suleman Hamad Altayalan, and saleh Al Quraishy (2013): Antimalarial drugs: Mode of action and status of resistance. African journal of pharmacology 7(5)pp. 148-156,DOI: 10.5897/AJPPX12.015.ISSN 1996-0816.

Shoback, edited by David G. Gardner, Dolores (2011).Green spans's basic \& clinical endocrinology $\left(9^{\text {th }}\right.$ ed.) new York: McGraw-Hill Medical.pp.chapter 17.ISBN 0-07-162243-8.

Salman MT, Ajayi P.O. Alagbonsi Al, Olatunji L.A (2017): Artesunate-induced hemolysis and hypoglycemia in rats: Gender implication and role of antioxidant enzymes J Appl Hematol 2017;8:23-32.

Szkudelski T. (2001): The mechanism of alloxan and streptozotocin action in B-cells of the rat pancrease. Physio Res.2001:50(6):537-46.PMID: 11829314

Townsend, DM., Tew, KD. and Tapiero, H .(2003) The importance of glutathione in human disease. Biomed. Pharmacother.,; 57:144-155.

Vahabzadeh M., and Mohammad pour HA (2015).Effect of Diabetyes mellitus on the metabolism of drugs and Toxins.J clin Toxicol 5.233 doi:10.4172/2161-0495.1000233.

Varshey R and Kale R. (1990). Effect of calmodulin antagonist on radiation induced lipid peroxidation in micosomes. International Journal Radiation Biology. 58(5):733-743.

White NJ, (1997): assessment of pharmacodynamics properties of antimalarial drugs in vivo. Antimicrob.Agents chemother. 41:1413-1422.

World Health Organization (1999): Definition, Diagnosis and Classification of Diabetes Mellitus and its Complications, Department of Non-communicable Disease Surveillance, Geneva WHO/NCD/NCS/99.2

World Health organization (2006): 'Definition and diagnosis of diabetes mellitus and intermediate hyperglymecia. Report of WHO /IDF consultation. ISBN 978-92-4-159493-6.

World Health Organization (2016). Global report on Diabetes 2016,88. 
WHO, World malaria Report (2014). Geneva, World Health organization.

WHO, World malaria Report (2016). Geneva, World Health organization.

Yang YZ, Asawamahasakda W, Meshnick SR (1993): Alkylation of human albumin by the antimalarial artemisinin. Biochem. Pharmacol 46:336-339.

Yang YZ, Little B, Meshnick SR (1994). Alkylation of proteins by artemisinin. Effects of heme, pH, and drug structures. Biochem. Pharmacol.48.569-573.

Zelko I., Mariani T., Folz R. (2002). 'Superoxide dismutase multigene family : a comparison of the Cuzn - SOD (SOD1), Mn- SOD (SOD2), and EC- SOD (SOD3) gene Structures, evolution, and expression' Free radic Biol Med 33 (3) : 337- 49. 